\title{
Occurrence of Helotropha leucostigma Hübner (Lep., Noctuidae) on maize in Rzeszów region
}

\author{
Występowanie Helotropha leucostigma Hübner (Lep., Noctuidae) \\ na kukurydzy w okolicach Rzeszowa
}

\author{
Paweł K. Bereś ${ }^{1}$, Tomasz Konefał ${ }^{2}$
}

\section{Summary}

Caterpillars of Helotropha leucostigma Hübner were found for the first time on maize plants (Zea mays L.) in Rzeszów region (south-east Poland) in 2008. In 2008-2012, every year in May and June a small number of caterpillars of this species were recorded on the maize fields, where they totally destroyed single plants at the stage of 4 to 6 leaves (BBCH 14-16). During the study years totaly 30 caterpillars of this species were found in four villages: Krzeczowice, Terliczka, Nienadówka and Głuchów. So far $H$. leucostigma has not been regarded as a pest of cultivated plants in Poland. The fact that during a few years the caterpillars of this moth were recorded in maize crops may indicate that the species $\mathrm{H}$. leucostigma has adapted to feeding on maize and therefore extended the range of its host plants.

Key words: Helotropha leucostigma, Zea mays, Poland, first record

\section{Streszczenie}

Gąsienice Helotropha leucostigma Hübner po raz pierwszy zostały stwierdzone na roślinach kukurydzy (Zea mays L.) w okolicach Rzeszowa (południowo-wschodnia Polska) w 2008 roku. W latach 2008-2012 corocznie, w okresie maja i czerwca obserwowano występowanie nielicznych gąsienic tego gatunku na polach kukurydzy, które całkowicie niszczyły pojedyncze rośliny w fazie od 4 do 6 liści (BBCH 14-16). Łącznie, w latach badań, w czterech miejscowościach: Krzeczowice, Terliczka, Nienadówka oraz Głuchów stwierdzono obecność 30 gąsienic tego gatunku. Dotychczas $H$. leucostigma nie była zauważona w Polsce na roślinach uprawnych. Kilkuletnia obecność gąsienic tego motyla na polach kukurydzy może świadczyć o przystosowaniu się gatunku do żerowania na kukurydzy, a tym samym poszerzeniu zakresu roślin żywicielskich.

Słowa kluczowe: Helotropha leucostigma, Zea mays, Polska, pierwsze stwierdzenie

\footnotetext{
${ }^{1}$ Instytut Ochrony Roślin - Państwowy Instytut Badawczy

Terenowa Stacja Doświadczalna

Langiewicza 28, 35-101 Rzeszów

pawel.beres@iorpib.poznan.pl

${ }^{2}$ Główny Inspektorat Ochrony Roślin i Nasiennictwa

Centralne Laboratorium

Żwirki i Wigury 73, 87-100 Toruń
} 


\section{Wstęp / Introduction}

Kukurydza (Zea mays L.) jest jedną z ważniejszych roślin zbożowych w Polsce, której areał uprawy w 2011 roku przekroczył 700 tys. ha (GUS 2011).

Wraz z rosnącą powierzchnią zasiewów tej rośliny, intensyfikacją produkcji oraz stosowaniem uproszczeń w agrotechnice wzrasta ryzyko pojawu szkodników i strat w plonach przez nie powodowanych (Lisowicz i Tekiela 2004).

Szkodniki towarzyszyły kukurydzy niemal od samego początku uprawy tej rośliny na ziemiach polskich. Jak podaje Kania (1962a, b) już w latach 50. XX wieku na kukurydzy żerowało ponad 20 gatunków szkodliwych owadów, które powodowały uszkodzenia zarówno nadziemnych, jak i podziemnych części roślin. Aktualnie do najważniejszych szkodników kukurydzy w Polsce zalicza się: omacnicę prosowiankę (Ostrinia nubilalis Hbn.), ploniarkę zbożówkę (Oscinella frit L.), mszyce (Aphididae), rolnice (Agrotinae), drutowce (Elateridae) i pędraki (Melolonthinae) (Bereś i Pruszyński 2008). Ważnym gatunkiem jest także stonka kukurydziana (Diabrotica virgifera LeConte), która uznawana jest za organizm kwarantannowy w Unii Europejskiej (Sahajdak i wsp. 2006).

Obok powszechnie znanych szkodników coraz częściej na plantacjach kukurydzy pojawiają się nowe gatunki, które dotychczas nie występowały na tej roślinie. Ich pojaw ma często charakter lokalny, a liczebność jest na tyle niska, że nie powodują one strat w plonach. Większość nowych gatunków należy do rzędu Lepidoptera, czego przykładem są między innymi: słonecznica orężówka (Helicoverpa armigera Hbn.), włócznica białożyłka (Simyra albovenosa Goeze), wieczernica szczawiówka (Acronicta rumicis L.), piętnówka brukwianka (Lacanobia oleracea L.) oraz znamionówka tarniówka (Orygia antiqua L.) (Bereś 2011).

Znaczna część gatunków, jaka pojawiła się w ostatnich latach na polach obsianych kukurydzą jest charakterystyczna dla terenów leśnych i podmokłych. Jednym $\mathrm{z}$ nich jest także Helotropha leucostigma syn. Celaena leucostigma Hübner (Lepidoptera, Noctuidae).

Celem pracy jest przedstawienie wyników z monitoringu występowania nowego gatunku owada $-H$. leucostigma na plantacjach kukurydzy w okolicach Rzeszowa, w tym wstępnych obserwacji na temat jego żerowania i powodowanych uszkodzeń roślin.

\section{Materiały i metody / Materials and methods}

Monitoring obecności szkodliwej entomofauny kukurydzy w województwie podkarpackim (południowowschodnia Polska) prowadzony jest przez Terenową Stację Doświadczalną Instytutu Ochrony Roślin - Państwowego Instytutu Badawczego w Rzeszowie (TSD IOR - PIB) od kilkudziesięciu już lat. Corocznym obserwacjom poddawane są plantacje kukurydzy zlokalizowane między innymi w następujących miejscowościach: Boguchwała, Głuchów, Kamień, Krzeczowice, Łąka, Mikulice, Niechobrz, Nienadówka, Radymno, Rzeszów, Stobierna, Terliczka, Trzeboś,
Trzebownisko oraz Trzebuska. Dodatkowo prowadzi się okazjonalne wizytacje pól kukurydzy w różnych częściach województwa $\mathrm{w}$ ramach konsultacji z rolnikami uprawiającymi tą roślinę.

W latach 2008-2012 w każdej monitorowanej miejscowości w zależności od wielkości plantacji kukurydzy dokładnym obserwacjom poddawano od 100 do 200 kolejnych roślin w rzędzie w pięciu miejscach pola po przekątnej (razem 500-1000 roślin). Obserwacje wykonywano 2-3 razy w tygodniu począwszy od wschodów roślin (kwiecień) aż po zbiór plonu ziarna (październik).

$\mathrm{Z}$ chwilą stwierdzenia obecności roślin zasiedlonych przez dotąd niezidentyfikowany gatunek owada oznaczano je plastikowym znacznikiem widocznym ponad wierzchołkami roślin i dokładnie obserwowano 2-3 razy w tygodniu zarówno rozwój agrofaga na tle zmieniających się faz rozwojowych kukurydzy, jak również powodowane przez niego uszkodzenia tkanek. Ponadto po zakończeniu żerowania fitofaga mierzono długość kanału żerowego w łodygach zasiedlonych roślin.

Plantacje kukurydzy zlokalizowane w czterech miejscowościach: Krzeczowice, Terliczka, Nienadówka oraz Głuchów, w których wykryto obecność H. leucostigma, miały powierzchnię od 0,5 do 20 ha i prowadzone były w systemie zmianowania. W miejscowościach tych, w latach badań uprawiano łącznie następujące odmiany kukurydzy: San, DKC3420, Clarica, Ronaldinio, Nekta, DKC2960, Monumental oraz Moncada.

W odniesieniu do gatunku $H$. leucostigma, zebrane $\mathrm{z}$ roślin dorosłe gąsienice przetrzymywane były w doniczkach razem $\mathrm{z}$ roślinami kukurydzy $\mathrm{w}$ izolatorach entomologicznych umieszczonych $\mathrm{w}$ warunkach laboratoryjnych $\mathrm{w}$ temperaturze $22 \pm 5^{\circ} \mathrm{C}$ i wilgotności względnej powietrza $70 \pm 10 \%$. Po zakończeniu żerowania gąsienice schodziły do gleby, gdzie przepoczwarczały się. Po wylocie motyle były uśmiercane octanem etylu i rozpinane. Identyfikacji owadów dorosłych dokonał prof. Jarosław Buszko z Uniwersytetu Mikołaja Kopernika w Toruniu.

\section{Wyniki i dyskusja / Results and discussion}

W wyniku monitoringu występowania szkodliwej entomofauny kukurydzy prowadzonego przez TSD IOR PIB w Rzeszowie, w 2008 roku po raz pierwszy w rejonie badań stwierdzono na roślinach kukurydzy w miejscowości Krzeczowice żerowanie gąsienic $H$. leucostigma. Łącznie w tej miejscowości wykryto 3 gassienice tego gatunku. W kolejnym roku badań obecność $H$. leucostigma odnotowano ponownie w Krzeczowicach oraz w Terliczce, gdzie znaleziono odpowiednio 5 i 2 gąsienice tego motyla. Szczególnie dużą liczebność fitofaga zaobserwowano jednak w latach 2010-2011, gdy gąsienice stwierdzono w czterech miejscowościach: Terliczce, Krzeczowicach, Głuchowie oraz w Nienadówce. W ówczesnym okresie znaleziono łącznie 14 gąsienic: po 2 osobniki w Terliczce i Głuchowie, 7 w Krzeczowicach oraz 3 w Nienadówce. W 2012 roku H. leucostigma pojawiła się tylko w Krzeczowicach i Nienadówce, gdzie odnotowano odpowiednio 4 i 2 gąsienice tego motyla. 
W odróżnieniu od większości gąsienic $\mathrm{z}$ rodziny Noctuidae, jakie spotyka się na plantacjach kukurydzy, osobniki $H$. leucostigma pojawiały się na początku okresu wegetacji, gdy rośliny rozwijały od 4 do 6 liści właściwych (faza BBCH 14-16) (Adamczewski i Matysiak 2011), co przypadało w okresie od drugiej dekady maja do drugiej dekady czerwca. Kukurydza uszkadzana przez ten gatunek w większości przypadków znajdowała się w pasach brzeżnych pola, w odległości do 10 metrów od brzegu. Zaobserwowano ponadto, że uszkodzenia roślin miały charakter placowy, co mogło być związane z występowaniem w danym miejscu większej liczby jaj szkodnika, z których wylęgły się gąsienice. Był to także efekt migracji gąsienic. Na podstawie dokładnych obserwacji stwierdzono, że gąsienice po uszkodzeniu jednej rośliny przemieszczają się po powierzchni gleby i zasiedlają kolejną, bezpośrednio sąsiadująca, co jest między innymi charakterystyczne dla rolnic.

Wizualne objawy żerowania $H$. leucostigma na kukurydzy były niemal identyczne z uszkodzeniami powodowanymi przez typowe szkodniki glebowe, takie jak: drutowce (Elateridae), pędraki (Melolonthinae) oraz rolnice (Agrotinae). Uszkodzone rośliny stopniowo więdły, żółkły, a następnie zasychały. Były to typowe objawy informujące o zakłóconym przepływie wody z korzeni do nadziemnych części roślin. W odróżnieniu jednak od szkodników glebowych stwierdzanych na kukurydzy, gąsienice H. leucostigma nie uszkadzały systemu korzeniowego roślin, lecz żerowały w łodygach drążąc w nich kanały. We wszystkich stwierdzonych przypadkach, gąsienice wgryzały się do wnętrza łodygi tuż przy jej nasadzie, w odległości do $5 \mathrm{~mm}$ nad powierzchnią gleby. W miejscu wgryzienia znajdował się niewielki otwór, który zazwyczaj był mało widoczny z uwagi na grudki gleby znajdujące się obok. W podobny sposób do roślin kukurydzy wgryzają się również drutowce.

W łodygach uszkodzonych roślin kukurydzy zawsze znajdowała się tylko jedna gąsienica $H$. leucostigma, która wyjadała rdzeń łodygi od jej nasady aż do stożka wzrostu. W zależności od wysokości rośliny, długość kanału żerowego wygryzanego przez gąsienice w łodygach zawierała się $\mathrm{w}$ przedziale od 4,2 do $21,5 \mathrm{~cm}$ długości (średnio $11,7 \mathrm{~cm}$ ) dla wszystkich lat badań. Zniszczeniu ulegały także zawiązki przyszłych liści, które były zjadane przez gąsienice zanim zdążyły się rozwinąć. Przy silnym zniszczeniu wiązek przewodzących dochodziło do łamania się łodyg tuż u ich nasady. Wszystkie rośliny uszkodzone przez $H$. leucostigma w badanym pięcioleciu uległy całkowitemu zniszczeniu, stąd też przy liczniejszym wystąpieniu gatunek ten może potencjalnie stanowić poważne zagrożenie dla młodych roślin kukurydzy.

Zebrane w czerwcu dojrzałe gąsienice umieszczano w izolatorach entomologicznych, w których po zakończeniu żerowania migrowały do gleby na głębokość do $7 \mathrm{~cm}$, gdzie się przepoczwarczały. Niemal wszystkie gąsienice schodziły do gleby w tym samym czasie, tj. pod koniec drugiej lub w trzeciej dekadzie czerwca. Wyloty motyli obserwowano z kolei w pierwszej lub drugiej dekadzie lipca.

H. leucostigma nie jest wykazywana w krajowej literaturze jako szkodnik jakiejkolwiek rośliny uprawnej, nie jest to jednak gatunek nowy dla polskiej fauny. Buszko i Nowacki (2000) stwierdzili jego występowanie na obszarze całego kraju. Owad ten był notowany m.in. w Karkonoszach oraz w lasach województwa wielkopolskiego (Nowacki 1998; Wąsala 2005). Thompson i Nelson (2003) podają że H. leucostigma jest gatunkiem szeroko rozpowszechnionym w Europie zachodniej, stwierdzanym od Francji po Szwecję i Finlandię. Zasiedla niemal cały obszar Wielkiej Brytanii, a także północną część Irlandii (Kimber 2013).

Owad występuje głównie w lasach i na terenach podmokłych (Thompson i Nelson 2003; Jansen 2005).

Brakuje informacji o szkodliwości tego gatunku dla roślin uprawnych, w tym kukurydzy. Jak podają Thompson i Nelson (2003) oraz Nawrot (2008) głównymi roślinami żywicielskimi dla $H$. leucostigma są: Iris pseudacorus L., Sparganium spp., Carex spp. oraz Acorus spp. Thompson i Nelson (2003) informuja ponadto o sposobie żerowania tego fitofaga, którego gąsienice wgryzają się do wnętrza łodyg swoich podstawowych roślin żywicielskich drążąc w nich kanały. Podobny obraz żerowania stwierdzono w badaniach własnych na kukurydzy.

$\mathrm{Na}$ monitorowanych polach kukurydzy gąsienice H. leucostigma występowały w okresie od maja do czerwca, niemniej Thompson i Nelson (2003) wskazują, że w warunkach Irlandii Północnej (klimat umiarkowanie morski wilgotny) gąsienice mogą żerować od marca do lipca. Cytowani autorzy podają również, że stadium zimującym tego gatunku są jaja, natomiast okres lotu motyli trwa od lipca do początku września. Początek wylotu motyli jest zbieżny $\mathrm{z}$ obserwacjami własnymi prowadzonymi w izolatorach entomologicznych.

\section{Wnioski / Conclusions}

1. H. leucostigma jest kolejnym przedstawicielem rodziny Noctuidae, który może uszkadzać rośliny kukurydzy. Gatunek ten nie był dotychczas notowany jako fitofag żerujący na kukurydzy w Polsce.

2. Coroczne występowanie $H$. leucostigma na polach kukurydzy w latach 2008-2012 może świadczyć o poszerzeniu zakresu roślin żywicielskich o kukurydzę (Zea mays L.).

3. W sytuacji dużej liczebności, H. leucostigma może stanowić znaczne zagrożenie dla kukurydzy, gdyż każda uszkodzona przez gąsienice roślina zamiera.

4. H. leucostigma powinna być objęta corocznym, szczegółowym monitoringiem występowania na plantacjach kukurydzy w innych regionach kraju wraz z rozpoznaniem pełnego cyklu rozwojowego na tej roślinie.

\section{Podziękowania / Acknowledgements}

Autorzy składają serdeczne podziękowania Panu prof. Jarosławowi Buszko z Uniwersytetu Mikołaja Kopernika $\mathrm{w}$ Toruniu za pomoc w identyfikacji gatunku. 


\section{Literatura / References}

Adamczewski K., Matysiak K. 2011. Kukurydza. s. 27-30. W: „Klucz do Określania Faz Rozwojowych Roślin Jedno- i Dwuliściennych w skali BBCH” [K. Adamczewski, K. Matysiak - tłumaczenie i adaptacja]. Inst. Ochr, Roślin - PIB, Poznań, 132 ss.

Bereś P.K. 2011. Mniej znane gatunki z gromady owadów (Insecta) zasiedlające rośliny kukurydzy (Zea mays L.) w południowowschodniej Polsce w latach 2005-2010. Prog. Plant Prot./Post. Ochr. Roślin 51 (1): 21-27.

Bereś P.K., Pruszyński G. 2008. Ochrona kukurydzy przed szkodnikami w integrowanej produkcji. Acta Sci. Pol., Agricultura 7 (4): $19-32$.

Buszko J., Nowacki J. 2000. The Lepidoptera of Poland. A Distributional Checklist. Polish Entomological Monographs, 1, 178 pp.

Główny Urząd Statystyczny (GUS) 2011. Użytkowanie gruntów, powierzchnia zasiewów i pogłowie zwierząt gospodarskich w 2011 r. Główny Urząd Statystyczny, Warszawa, 183 ss.

Jansen M.G.M. 2005. The Lepidoptera fauna of three brackish salt marshes including two species new for the Belgian fauna (Lepidoptera). Phegea 33 (2): 59-68.

Kania C. 1962a. Szkodliwa entomofauna kukurydzy obserwowana w okolicach Wrocławia w latach 1956-1959. Część I. Pol. Pismo Entomol., Seria B, 1-2 (25-26): 53-69.

Kania C. 1962b. Szkodliwa entomofauna kukurydzy obserwowana w okolicach Wrocławia w latach 1956-1959. Część II. Pol. Pismo Entomol., Seria B, 3-4 (27-28): 183-216.

Kimber I. 2013. UK Moths. The Crescent Celaena leucostigma. Dostępny w internecie: http://ukmoths.org.uk/show.php?bf=2368\& map=true. Dostęp: 09.03.2013.

Lisowicz F., Tekiela A. 2004. Szkodniki i choroby kukurydzy oraz ich zwalczanie. s. 52-64. W: „Technologia Produkcji Kukurydzy” (A. Dubas, red.). Wieś Jutra, Warszawa, 133 ss.

Nawrot J. 2008. Leksykon Owadów. Inst. Ochr. Roślin, Poznań, 551 ss.

Nowacki J. 1998. Sówkowate (Lepidoptera: Noctuidae) Karkonoszy Polskich. Wiad. Entomol. 16 (3-4): 177-188.

Sahajdak A., Bereś P.K., Konefał T. 2006. Diabrotica virgifera LeConte - a new threat to maize crops in Poland and measures taken against the pest. J. Plant Prot. Res. 46 (2): 157-161.

Thompson R., Nelson B. 2003. The butterflies and moths of Northern Ireland. National Museums Northern Ireland. Dostępny w internecie: http://www.habitas.org.uk/moths/species.asp?item=6473. Dostęp: 05.11.2012.

Wąsala R. 2005. Sówkowate (Lepidoptera: Noctuidae) Leśnego Zakładu Doświadczalnego Siemianice. Wiad. Entomol. 24 (2): $89-111$. 